ARID International Journal of Social Sciences and Humanities (AIJSSH) VOL.2, Special Issue (1), August 2020

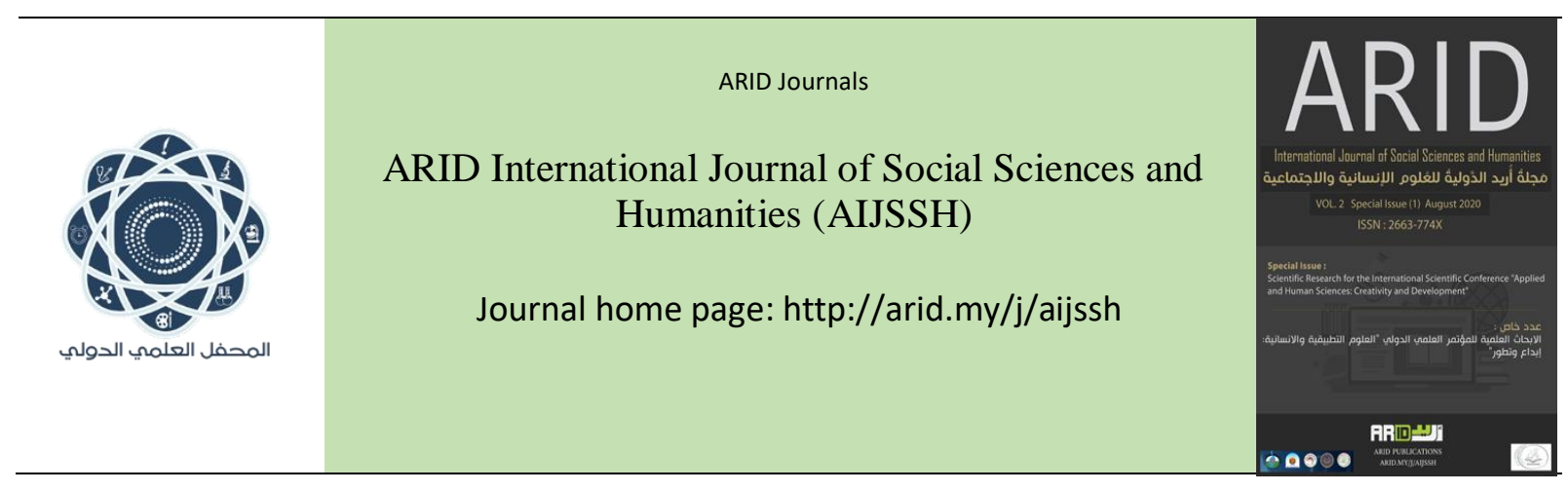

$$
\begin{aligned}
& \text { مَجلةُ أُريد الدَّوليةُ للعُلورج الإنسانية والإجتماعية } \\
& \text { المجلد الثاني ،العدد الخاص ، آب } 2020 \text { م }
\end{aligned}
$$

\title{
Legal protection for the national product from commercial dumping
}

$$
\text { الد.دينة غانم يونس العبيدي* }
$$

$$
\text { فرع حقوق الإنسان- كلية الحقوق - جامعة الموصل }
$$

arid.my/0005-4316

https://doi.org/10.36772/arid.aijssh.2020.s.2112 


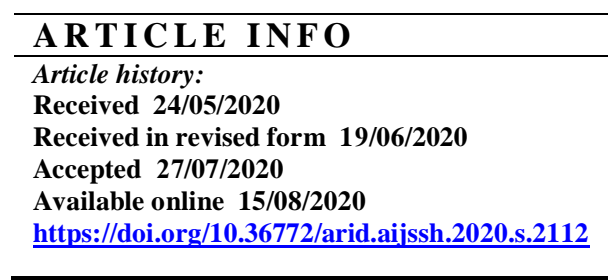

\begin{abstract}
Commercial relationship, always take place when the foreign and importer illegal competition Domestic product at less than normal value or cost in another country, its perfume negative effects for the Domestic producer, consumer and foreign too, so three, legislator must be intervene to confrontation commercial Dumping crackdown which give right to obligate Extra Duty unless normal duty against exports in the State .
\end{abstract}




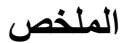

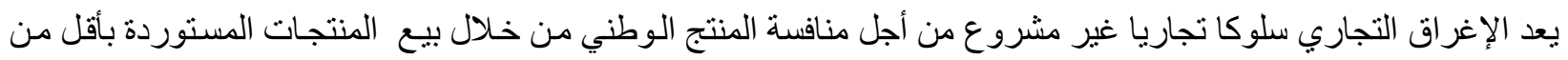

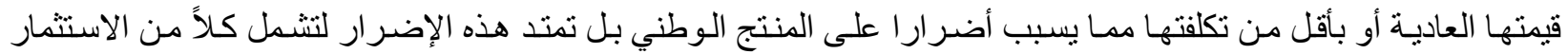

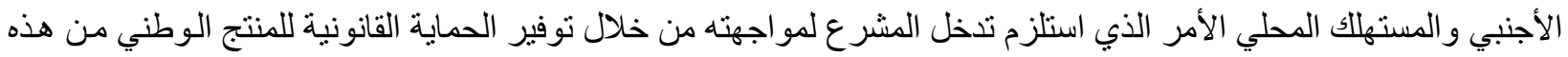

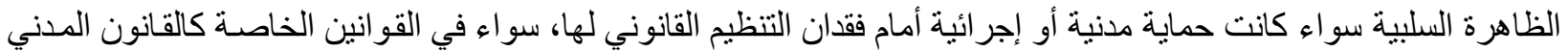
أو قانون المر افعات المدنية أو في قانون حماية المنتجات العراتية الفية. 


\section{أولا : مدخل تعريفى للموضوع:}

يعد الإغراق من المشاكل الخطيرة على الاقتصاد الوطني وخاصة المنتج الوطني واستقرار الأسواق المحلية فضـا عن تأثير هـا السلبي على أطر اف التعامل التجاري سو اء كانوا منتجين أو مستهلكين من أجل السيطرة على أسواق معينة و التحكم بها، يحقق مصالحهم على حساب أي مصلحة أخرى وهي الاقتصاد المحلي فيترك أثرا هاما وخطبر او هو انخفاض سعر المنتج المستورد مقابل الأضر ار بالمنتج الوطني عند انتاجه لمنتجات منتابهة، و عليه فإن الإغراق هو توريد السلع المماتلـة إلى السوق المحلي بسعر أقل من قيمتها العادية في سوق البلد المورد وقد يكون إغر اقا مؤقتا أو دائما.

\section{ثانيا :أهمية الموضوع و أسباب اختياره:}

تكمن أهمية البحث في غزو الأسواق المحلية بالبضائع المستوردة بسعر أقل مما يكلفه إنتاج السلحع المحلية وهذا ذو تنأثير سلبي على الاقتصـاد الوطني ممـا يتطلب توفير حمايـة قانونية للمنتج الوطني سواء كانت حمايـة مدنية أو إجرائية فضـلا عن ندرة الكتابات القانونية بهذا الجانب، كل هذا كان دافعـا لتسليط الضوء على هذا الموضوع الحيوي و إيجاد الحلول المناسبة للقضـاء على هذه الظـاهرة السلبية مقابل خلو التنظيم القانوني لهذه الحمايـة في ظل أحكام القانون المدني العر اقي وقانون المر افعات

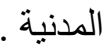

\section{ثالثا : منهجية البحث}

سوف نتبع الأسلوب التحليلي في طرح هذا الموضوع من خلال تحليل النصوص القانونية الواردة في قانون في فانون حمايـة المنتجات العر اقية رقم 11 لسنة 2010 ونصوص اتفاقية مكافحة الإغراق الجـات 1994 من أجل الوصسول إلى تنظيم قانوني يتعلق بالحماية القانونية للمنتج الوطني.

\section{رابعا: خطة البحث}

سوف نقسم البحث إلى ثلاثنة مباحث مخصصين المبحث الأول: لمفهوم الإغراق التجاري للمنتج الوطني وذلك في ثلاثـة مطالب، خصصنا المطلب الأول لتعريف الإغراق التجاري لغة واصطلاحا وتناولنا في المطلب الثاني أنواع الإغراق التجاري أما عناصره فتطرقنا إليها في المطلب الثالث، أمـا في المبحث الثاني فتناولنا فيه الحمايـة المدنية للمنتج الوطني من الإغراق وذللك في مطلبين نتناول في المطلب الأول: شروط قبول دعوى الحماية المدنية للمنتج الوطني . 
وفي المطلب الثاني: سوف نتناول فيه أثر دعوى الحمايـة المدنية للمنتج الوطني أمـا المبحث الثالث: فسوف نخصصسه للحمايـة الإجر ائية للسلع المحلية من الإغراق التجاري مخصصين المطلب الأول: دعوى الإغراق التجاري وفي المطلب الثاني: سوف نتناول الوسائل البديلة لفض مناز عات الإغراق التجاري ثم أنهينـا بحثنا بخاتمـة، بيّنا فيهـا أهم النتائج و التوصيات التي توصلنا

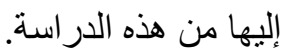

المبحث الأول الإغراق التجاري

\section{1-1-1 - مفهوم الإغراق التجاري}

سوف نتناول في هذا المبحث من حيث ماهية الإغراق لغة واصطلاحا واهم أنواع الإغراق و عناصره وذذلك بعد تقسيمه إلى ثلاثة مطالب نتناول في المطلب الأول تعريف الإغراق لغة واصطلاحا أما في المطلب الثاني فسوف نسلط الضوء على أنواع الإغراق التجاري ثم نحدد عناصره في المطلب الثالث .

\section{1-1-1 المطلب الأول / تعريف الإغراق التجاري لغة واصطلاحا}

من أجل تحديد مفهوم الإغراق التجاري لغـةُلابد أن ترجع إلى الأصل الثناثي لكلمـة الإغراق و أصلها في اللغـة غَرَقَ، و الغرق هو الرسوب في الماء، و أغرق نأتي بمعنى بالغ في الأمر وجاوز الحد كما يأتي بمعنى الاستبعاد، والتغريق أيضا مطلق القتل. [2]ويقال رجلٌ غرق وغريقٌ وقد غرق غرقاو هو غارق، قال أبو النجم : فأصبحوا في المساءِ والخنادقي من بين مقتول.

$$
\text { وطافٍ غارق والجمع غرقه وهو فَعيل. [1] }
$$

أما عن تعريف الإغراق اصطلاحا فقد اختلف الفقه. [5] في تعريفه في اتجاهات عدة، منهم من عرّفهُ بأنها بيع منتج في سوق دولة ما بسعر أقل مما يباع به داخل سوق الدولة المصنعة له، وعرّفه آخرون بشكل آخر بالقول بأنسه بيع منتج مـا داخل سوق دولة أخرى بأقل من سعر التكلفة.

يتضح لنا من هذين التعريفين بأن المنتج يكون بموجبها مغرقا حتى لو لم يسبب ضرر اللمنتج الوطني، ومن وجهة نظرنـا المتو اضعة نجد إن هذا القول غير دقي، لذلك عرّفه آخرون بصيخه أخرى و اعتبره بيعاً بمقادير ضخمه وبأسعار أقل من السعر المعتاد وذللك بهدف التغلب على المنافسين و السبطرة على السوق [6]،ومع تقديرنا لهذا التعريف إلا أنه جاء ضبقاً للمعنى الحقيقي للإغراق لأنه حدد هدف المغرق وهو التغلب على المنافسين والسيطرة على السوق وهذا جزء من غايات الإغراق لا 
كلها، لأن الهدف قد يكون تصريف للمنتج الوطني أو إيجاد سوق خارجي لها أو المحافظه على وجودهـا في الأسواق الخارجيـة أو تصريف الفائض من المنتج الوطني و غير ها من أهداف أخرى لاتقع تحت حصر .

و عرفُه آخرون بأنه: بيع السلعة في أسواق الدول الأخرى بأسعار أقل من السعر الذي تبـاع بـه السلعة نفسها في السوق المحلية في الوقت نفسه وظروف الإنتاج نفسها مع مر اعاة تكاليف النقل. [7] لو قارنّا هذا التعريف بالتعاريف السابقة نجده واسعا نو عا ما إلا أنه استند إلى ظرف الإنتاج وهذا لا يؤثر على الإغراق وذلك لأن تشـابه أو اختلاف ظرف الإنتاج كوفرة المواد الأوليـة أو اليد العاملـة لا فائدة منـه في تحديد إغر اقيـة المنتج لذلك أعطى البعض الآخر ـ [10]مفهوما مغاير ال للإغراق وذللك بالقول : إن رسوم الإغراق تفرض إذا كان سعر تصدير المبيعات أقل من قيمتها في السوق الأجنبي. وتعتمد تكلفة الإنتاج إذا كانت القيمـة في السوق الأجنبي غير مناسبة أو غير محققة ويجب أن يكون للإغر اق علاقة بضرر مادي تعانيه الصناعة المحلية. إلا إن هذا التعريف محل نظر وذللك لأنه جاء بصيغة شرح للإغراق وليس تعريفا، لأن التعريف يجب أن يكون جامعا مانعا. أما تعريف الإغراق لدى التشريعات فقد جاء في الفقرة (4) من المـادة (1) من قانون حمايـة المنتجات العر اقيـة رقم 11 لسنة 2010 تعريفا للإغراق بأنه : توريد السلع الممانتلة إلى السوق المحلية بسعر أقل من قيمنها العادية في سوق البلد المورد. مع تقديرنا لموقف المشرع العر اقي في تحديد مفهوم الإغراق إلا إننا لا نتفق معه لسببين الأول:هو أن التعريف ليس من مهام المشرع، كان الأولى بالمشرع العر اقي أن يترك للفقهاء والثر اح و الكتاب المختصين وضع التعريف، أمـا السبب الثاني فقد أخفق المشرع العر اقي في اختياره لعبار ات التعريف تحديدا كلمة توريد والتي هي مر ادفا لكلمـة تصدير فإنها تعني بأن القائم بفعل الإغراق هو الوطني سواء أكان شخصا عاما أو خاصا وفي حقيقة الأمر قد لايكون كذلك دائما، إذ يمكن أن يمارس الفعل الأجنبي كذلك . من كل ما تقدم بمكننا أن نقترح تعريفا للإغراق جامعا مانعا وكالآتي: يعد الإغراق مؤقتا كان أم دائميا ممارسة تجارية غير مشروعة تُباع فيها منتج أجنبي أو تقدم خدمات في أسواق دولة ما بكميات كبيرة وبثمن أقل من ثمنه في أسواق دولة المنشأ أو دولة ثالثة أو أن يقل عن تكلفة إنتاجه مسببا أضرارا للمنتج الوطني المشـابه 
إن التعريف المقترح قد أعطى تكيّفا دقيقا للإغراق باعتباره ممارسة تجارية غير مشروعة، كما أنه حدّد لنا أنو اع الإغراق وهي المؤقت و الدائمي كما جاء مفهومه أوسع إذ شمل الخدمات و البضائع معا فضلا عن ذلك حدّ كيفية وقوع ممارسـة تجاريـة غير مشروعة، فضلا عن ذلك حدد كيفية وقوع الإغراق ذلك من خلال بيع المنتجات الأجنبية بكميات وفيرة وبأثمان أقل بكثير من أثمان المنتج الوطني المشـابه لـه ويترتب على ذللك إضـرار ا كبيرة للمنتج الوطني ممـا يتطلب توفير الحمايـة القانونيـة للمنتج الوطني

\section{2-1-1 المطلب الثاني / أنواع الإغراق}

بعد أن حدنا مفهوم الإغراق لغة واصطلاحا لابد إن نسلط الضوء على أنواع الإغراق حيث يكون الإغراق بنوعين:

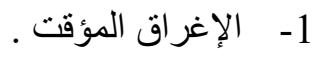

$$
\begin{aligned}
& \text { 2- الإغراق الدائم . } \\
& \text { فبالنسبة للإغراق المؤقت يكون هو الأخر على نوعين : }
\end{aligned}
$$

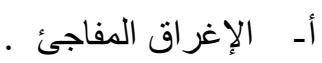

$$
\begin{aligned}
& \text { بــ الإغراق قصبر الأجل . }
\end{aligned}
$$

أما عن الإغر اق المفاجئ: فهو نوع من أنواع الإغراق إلا أنه يستهدف سوق معنيـة أو بلد بصفة دائمـة فيقع بظرف طـارئ كالزيادة الحاصلة في عرض منتج معرض للكساد أو حالة وجود فائض منر اكم من محصول أو سلعة، و هذا النوع من الإغراق مرتبط بالتخلص من المنتجات الزائدة من الإنتاج فهو قصير المدة لحد كبير قد لا ينتج عنه آثار الإغراق فهو لا يحمل في طياته نية الإضرار بالإنتاج المحلي . [17] في حين إن النوع الآخر من الإغراق هو الإغراق قصير الأجل، وبموجب هذا النوع من الإغراق يعمد التاجر أو المستورد إلى بيع سلعة بأسعار منخفضة ولفترة محدودة و هنا يتحمل المغرق خسائر كبيرة على أمل تحقيق أرباح مستقبلية بعد القضـاء على منافسيه في السوق.

مها تقدم تبين لنا هذا النوع من الإغراق التجاري يهدف إلى تحقيق هدف معين ينتهي بمجرد تحقيق الهدف، لذلك يسمى [9الإغراق الهجومي . [9] أما النوع الثاني من الإغراق هو الإغراق الدائم: 
حيث يستمر بيع السلع في السوق الخارجية بسعر أقل من السعر المحلي أو بتكلفة الإنتاج [16] وهذا النوع يكون وفقا لخطة طويلة الأمد و السؤال الذي يتبادر إلى الأذهان هو:

$$
\text { أي نوع من الإغراق يعد خطير اويؤثر سلبا على المنتج الوطني؟ }
$$

من وجهة نظرنا المتواضعة نعتقد إن الإغراق القصير الأجل هو أكثر خطورة على المنتج الوطني من أنواع الإغراق التجاري الأخرى، وذلك لأن الإغراق الدائم يمكن مكافحته من خـلال فرض الرسوم بينمـا لا يمكن ذلك في الإغراق القصبر الأجل لقصور مدته فضلا عن ذلك فإن الإغراق الدائم فيه فائدة للمستهلك أو المنتج المحلي الذي ينتج سلع معتمد على السلعة المغرقة كمادة رخيصة الثمن تدخل في صناعتهم فهذه الفائدة أكبر من ضرر الإغراق على المنتج الوطني المماثل وهذا الاحتمـال لا وجود له في الإغراق القصير الأجل .

\section{3-1-1 المطلب الثالث / عناصر الإغراق}

بعد أن بينا ماهيـة الإغراق و أنواعـ ارتأينا في هذا المطلب تحديد عناصر الإغراق و التي لابد من وجودهـا من أجل أن يتحقق وجود الإغراق ويمكننا إجمال هذه العناصر بثلاثة: أو لا: هو فحل الإغراق ويتحقق ذلك بوجود منتج يتم تصديرهُ من دوله ما و إدخاله بأقل من قيمته العادية حيث ينم بيعهُ في دولـة التصدير بسعر أقل من السعر المقابل لمنتوج وطني مماتل له يباع في دولة التصدير ـ [18] ثانيا: أن يكون الإغراق غير مشروع: كي يتحقق الإغراق لا يكفي إدخال المنتج إلى دولة ما بأقل من قيمته العادية لبيعه بثمن أقل من ثمن المنتوج الوطني المماتل له لابد إن يكون الإغراق غير مشروع، بمعنى آخر يعد إغر اقا مشروعا الذي يتضمن هامش إغراق يقل عن 2\% من سعر التصدير ويعد حجم واردات الإغراق قلبِلا إذا كـان حجم الواردات المغرقـة في دولـه مـا يقل عن 30\% من واردات الدولـة [18] [ المستوردة من المنتج المماثل ـ 
ويتمثل بإلحاق ضرر بالمنتج المحلي فإن إدخال منتج إلى دولـة مـا بسعر أقل من القيمة العادية ووجود منتج محلي مماثل لا يتحقق الإغراق إلا بوقوع العنصر الثالث وهو إلحاق الضرر بالمنتوج الوطني وبعدمه لا يتحقق الإغراق. [19] المبحث الثاني

\section{الحماية المدنية للمنتج الوطني}

\section{1-2 الحماية المدنية للمنتج الوطني من الإغراق}

إن حماية المنتج الوطني يعد أهم مبرر لتوفير الحماية المدنية له وهذه الأخيرة لا تتحقق إلا بتو افر شروط قبول دعوى الحمايـة المدنية و الأثر المترتب عليها لذلك ارتائنا تقيم هذا المبحث إلى مطلبين مخصصين المطلب الأول لشروط قبول دعوى الحمايـة المدنية للمنتج الوطني أما المطلب الثاني فسوف نتناول فيه أثر دعوى الحماية المدنية للمنتج الوطني (التعويض ) . 1-1-2 المطلب الأول /شروط قبول دعوى الحماية المدنية للمنتج الوطني من أجل الإلمام بالموضوع لابد أن نتطرق إلى الخطأ والضرر والعلاقة السبيية بينهما: فبالنسبة للخطأ هو أمر لابد تحققه من أجل رفع دعوى الحماية المدنية بالصيغة التي يترتب عليها ضرر بـالمنتج الوطني فهل يعد الإغراق خطأ ؟! لو رجعنا إلى المـادة (1) من قانون حمايـة المنتجـات العراقية رقم 11 لسنة 2010 نجد أن الخطأ في فعل الإغراق يكمن في عملية تصدير أي منتج إلى بلد الاستير اد بثمن يقل عن القيمة العادية لمنتج مماثل أو مشـابه في السوق المحلية، بمعنى آخر إن فيام فعل الإغراق التجـاري غير المشروع من عدمـه يكون بمقارنة سـعر السلعة في البلد المستورد وسـر السلعة في البلد المصدر فبمجرد أن يكون سعر السلعتين مختلفتين فإن كانت القيمة العادية للسعلة أعلى من سعر التصدير، لايمكن القول بوجود إغر اق ولكن منى ما كان سعر تصدير السلعة أقل من القيمة العادية فإن ذلك يعد دليلا على تو افر فعل الإغراق التجاري غير المشروع، عليه من كل ما تقدم يمكننا أن نُعد الإغراق خطاً. أما عن الضرر، فكما نعلم إن الضرر بشكل عام هو أذى يصيب الثخص فيسبب خسارة مالية في أمواله سواء كانت ناتجة عن نقصها أو نقص منافعها أو زوال بعض أوصافها وكل ما يترتب عليه من نقص في قيمتها كما كانت عليه قبل وقوع الضرر [8] 


\section{فهل مفهوم الضرر هذا ينطبق على الضرر في دعوى الحماية المدنية للمنتج الوطني؟}

بالنسبة لقانون حماية المنتجات العر اقية رقم 11 لسنة 2010 لم يعرف أو يحدد الضرر، إلا إن اتفاقية مكافحة الإغراق التجاري في م 3 منها عرفت الضرر بأنه (الضرر المادي لصناعه محلية أو التهديد بإحداث ضرر مـادي أو التأخير المـادي لإقامـة مثل هذه الصناعة).

بتضح لنا من هذا النص أنه قد أثـار للضرر المادي فقط دون الضرر المعنوي وهذا محل نظر خاصـة، وأن النشـاطات التجاريـة تتأثر بشكل كبير بالسمعة التجاريـة لذلك نأمل من المشرع العر اقي أر اد التدخل بنص قانوني يشـمل الضـرر بنوعيـه المـادي و المعنوي، وذلك في قانون حماية المنتجات العر اقية على أن يكون النص بالثكل الأتي: (إذا تحقق الإغراق التجاري لزم التعويض عن ما يحدثه من أضرار مادية ومعنوية للمنتج الوطني ) كما تجدر الإشارة بأن هذا النص قد أشتار إلى التهديد أو التأخير و هنا يتمثل بأضر ار وشيكة الوقوع بسبب الاستمر ار في بيع السلع المستوردة في البلد المستورد بالمستوى و السعر نفسيهما وهذا بالتأكيد يؤدي إلى أضر ار مادية مستقبلية على المنتج الوطني، أمـا التأخبر فيتمثل بانعدام الجدوى الاقتصادية من إنشاء مشروع تجاري بسبب انخفاض أسعار السلع المغرقة. أما عن العلاقة السبيية فيجب أن يكون الضرر قدوقع بسبب الخطأ ويعد تو افر العلاقة السبيية بين فحل الإغراق التجاري غير المشروع و الضرر هي العنصر الفعال لغرض تدابير مكافحة الإغراق، لأن مجرد قيام فحل الإغراق وتحديده لا يعد كافيا ليمكن المنتج الوطني في البلد المستورد من رفع الدعوى إذ لابد أن يثبت أن الخطأ هو عله الضرر و لا تثير علاقة السبيية مشكلة متى ما كانت هي النتيجة النهائية للفعل، إلا أن المشكلة تُثار إذا تخلل فحل الإغراق أفعالا أخرى منتجة في إحداث الضرر و اجتمعت عدة أسباب في تحقيق النتيجة أو سـاهمت في تحقيقها عوامل أخرى كفعل الضرر أو فعل المتضرر، وذلك في حالة تحقيق الضرر جزء منه راجعاً إلى الإغراق وفي جزء آخر يعود إلى العوامل الأخرى الأجنبية عن فعل الإغراق .

2-1-2 المطلب الثاني / أثر دعوى الحماية المدنية للمنتج الوطني

\section{- - التعويض}

أشنار قانون حماية المنتجات العر اقية رقم 11 لسنة 2010 إلى تحديد المقصود بالإغراق وشروط تحققهِه وكيفية معالجته و الآثار المترتبة على الدعوى إلا أنه لم يتطرق إلى مسألة هامةُوهي التعويض، وهذا إن دل على شي إنما يدل على أنه قد ترك الأمر

$$
\text { إلى القو اعد العامة في القانون الوطني لكل دولة. }
$$


مما يؤكد ضرورة البحث في قو اعد المسؤولية المدنية لتعويض المتضرر من جر اء السلوك التجاري غير المشروع في التجارة الدولية وللمنتج الوطني الذي تعرض للضرر يتعذر تداركهُ كإغلاق مصنعهُ مطالبة المنتج الأجنبي و المستورد بتعويض يقابل تعادل قيمة ما يكلفهُ من إعادة إلى ما كان عليه قبل وقوعه ـ [13] ولعدم وجود أحكام خاصة بالتعويض من حيث تقديرهُ وشروطهُو عدم رجوع القو اعد العامة في القانون المدني العر اقي رقم 40 لسنة 1951 المعدل نقترح على المشرع العر اقي نص في قانون حمايـة المنتجات العر اقيـة يمنح الحق للمنتج الوطني المطالبة بالتعويض ونأمل أن يكون النص بالشكل الآتي: (يحق للمتضررين من الإغراق التجاري المطالبة بالتعويض إن كان لـه مقتضى ويخضـع تقديره للمحاكم الخاصـة في مسـائل الإغراق التجاري ) عليه فإن النص المقترح قد عالج مسألة التعويض عن الأضرار الو اقعة جرّاء الإغراق التجاري للمنتج الوطني فضـلا عن أنـه اقترح تشكيل محاكم متخصصة بالنشاط التجاري تنظر في مسائل الإغراق التجاري . المبحث الثالث

\section{الحماية الإجرائية للمنتج الوطني}

\section{1-3 الحماية الإجرائية للمنتج الوطني من الإغراق}

يعد الإغراق التجاري أحد صور المنافسة الغير مشروعة لذلك لابد من وجود آليات تحد منه وتعالجه حال وقو عـه، الأمر الذي يدفعنا للتساؤل عن مدى إمكانية إقامة دعوى الإغراق التجاري وما هو دور الطرق البديلة لحل النزاع في معالجـة هذه المسالة وما هو دور المشرع العر اقي في هذه الحالات ولغرض الإجابة عن هذه التساؤلات قسمنا هذا المبحث إلى المطالب الآتية :

\section{1-1-3 المطلب الأول / دعوى الإغراق التجاري}

على الرغم من أن قانون حماية المنتجات العر اقية [23] قد عرف الإغراق التجاري إلا أنه لم يثبر إلى دعوى الإغراق لا من حيث التنظيم ولا من حيث التعريف، ولدى الرجوع لقانون المر افعات العر اقي بوصفه القانون الإجر ائي العام نجد أنه عرف الدعوى بأنها (طلب شخص حقه من آخر أمام القضاء ) [24]و عليه يمكننا أن نعرف دعوى الإغراق التجاري بأنها طلب تتقدم به الجهة المعنية إلى القضاء للحصول على الحماية القضائية في حال تحقق الإغراق.

وييقى التساؤل مفتوحا عن مدى إمكانية رفع هذه الدعوى ومن هي المحكمة المختصـة بذللك ؟ لدى الرجوع إلى قانون حمايـة المنتجات العر اقية نجد أنه اقتصر على بيان آلية إثبات وجود الإغراق ووسيلة تقديم الطلب الى وزير الصناعة والمعادن للبدء 
بالتحقيقات، وإذا ثبت وجود الإغراق يصدر الوزير المختص قرارا بفرض تدابير نهائية لمعالجتها أو يـأمر بإصدار إجر اءات عاجلة تتضمن وضع تأمينات أو كفالة كما يمكن أن يتخذ التدابير الكفيلة بمكافحة الإغر اق من خلال فرض الرسوم الجمركية أو تحديد رسوم تعويضية أو اتخاذ تدابير وقائية أخرى .

ويأتي ذللك انسجاما مع اتفاقية الجات 1994 التي انظم إليها العراق ـ [12] ويلاحظ أن الإجر اءات التي نصّ عليها هذا القانون هي إجراءات تتفيذية لايمكن تطبيقها أمام المحاكم العر اقيـة، الأمر الذي يعد محل نظر لذلك نوصي المشرع العر اقي بإير اد باب خاص في قانون حماية المنتجات العر اقية عنو انهه دعوى الإغراق التجاري

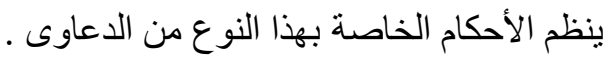

مـن ناحيـة أخرى نجـ أن المشـرع العر اقي استـدث محكمـة بـداءة خاصـة بالـدعاوى التجاريـة تختص بـالنظر في الـدعاوي التجارية، إذا كان أحد أطر افها أجنبيا أي من غير العر اقيين ويكون اختصاصها المكاني محافظة بغداد بحدودها الإدارية، أمـا طرق الطعن في إحكامها فيطبق بشأنها الأحكام العامة التي نص عليها قانون المر افعات العر اقي ـ [20] ويأتي ذلك انسجاما مـع أحكام القانون المدني العر اقي. [25]التي سدت بمقاضاة الأجنبي أمام المحاكم العر اقية إذا وجد في العراق وقت رفع الدعوى أو كان موضوع الدعوى عقدا تم إبرامه في العر اق أو كان واجب التنفيذ فيه.

وتعد هذه خطوة إيجابية من المشرع العر اقي تأتي استجابة للحاجة لوجود هكذا نوع من المحاكم في ظل الازدهار الاقتصسادي و الانفتاح التجاري على دول العالم فضلا عن التخصص القضائي الذي دعى إليه الفقه الحديث .

و على الرغم من وجود هذه المحاكم إلا إنتا لم نجد أب دعوى تتعلق بـالإغراق التجاري، لذلك ندعو إلى رفع الدعاوي المتعلقة بالإغر اق أمام هذه المحاكم في الوقت الحالي وندعو المشرع العر اقي إلى إنشاء محاكم اقتصادية متخصصة بالنظر في الدعوى التجارية، ونقترح إضافة النص الآتي إلى قانون السلطة القضـائية (تنعقد المحاكم الاقتصـادية في كل محكمـة استئنافية برئاسـة أحد أعضائها و عضوية عدد كافي من قضاتها تختص بالنظر في الدعاوي التجارية ودعاوي الإغراق التجاري ). ويقصد بالمحاكم الاقتصادية هي المحاكم التي تختص بالنظر في الدعاوي الاقتصـادية، وتضم قضـاة متخصصين يتم اختيار هم من بين قضاة المحاكم الإبتدائية وقضاة محاكم الاستئناف، ومن أهم دو اعي انشائها الحاجة إلى إجر اءات قضائية حديثنة تتناسب [15] [ مع الطبيعة الخاصة للمناز عات التجارية ـ وتتتابه المحاكم الاقتصادية مع المحاكم المدنية في إجراءاتها، إذ بطبق عليهما قو اعد قانون المر افعات المدنية باعتباره القانون الإجر ائي العام ـ و لا تخنلف عنها إلا في مسألة تحضبر الدعوى و الطعن في الأحكام . 
وقد نص على ذللك قانون المحاكم الاقتصـادية المصري ـ [26] إذ نصت المـادة (8) منـه (تنشـا بكل محكمة اقتصسادية هيئة لتحضير المناز عات والدعاوى التي تخنص بها هذه المحكمة وذلك فيما عدا الدعاوى الجنائية و الدعاوى المستانفة والأوامر (المنصوص عليها ............. وبذللك ينحصر نطاق تحضير الدعاوي على الدعاوي الغير جنائية التي ترفع ابتداء أمام المحاكم الابتدائية والاستئنافية. وحددت الفقرة الثالثة من المادة الثامنة من قانون المحاكم الاقتصادية اختصاصات هيئة التحضير التي تشمل التاكد من استيفاء مستندات الدعاوى، وعقد جلسات الاستماع لأطر افها وتحديد أوجه الخلاف و الاتفاق بينهم كل ذلك خلال ثلاثين يوما فضلا عن بذل محاو لات الصلح بينهم ـ [11] ونجد أن هذه الإجر اءات تتشـابه مـع نظام إدارة الدعوى المدنية الذي أخذ بـه القانون الأردني، والذي يهدف لعقد لقاءات بين الخصوم لحصر النزاع و استكمال الأدلة والمحاولة لعقد الصلح بين الطرفين. ونوصي المشرع العر اقي باتباع هذه النظم القضائية الحديثة التي من شأنها الحد من ظـاهرة بطء التقاضـي فضـلا عن انسجامها مع الطبيعة القانونية للاعوى التجارية .

\section{2-1-3 المطلب الثاني / دور الوسائل البديلة لحل النزاع في فض منازعات الإغراق التجاري}

على الرغم من الضمانات التي يحققها التقاضي إلا أن طول وشكلية هذه الإجراءات أدى للبحث عن وسـائل بديلـة لحل النزاع مثل التحكيم و الوساطة مما بدفعنا للتساؤل عن دور هذه الوسائل في فض مناز عات الإغر اق التجاري و هذا ما سنجيب عليه من

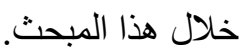
يقصد بالوسائل البديلة لحل النزاع مجمو عـة من الإجر اءات التي تشكل بديلا عن المحاكم في حل المنازعات غالبا تستوجب تدخل شخص ثالث نزيه وحيادي. [23] ومن هذه الوسائل التحكيم و الوساطة والتوفبق. وتجدر الإشارة إلى أن المشرع العر اقي نص على التحكيم في قانون المر افعات العر اقي ويعرفه الفقه بأنه (اتفاق على إناطـة حل مـا ينشـأ بين الأفراد على محكمين ليفصلو ا فيها بعيدا عن إجراءات القضـاء [3] [3] [3 [ كما نصت على أحكامة منظمة التجارة العالمية إذ تتشكل اللجان التحكيمية في حال تقديم طلب من الطرف المتضرر، ويجب أن يثيير إلى عقد المشاورات من عدمها مع تحديد مواضع النزاع. وتقوم هذه اللجان التحكيمية بمحموعة من الإجراءات، تبدأ 
بدر اسة الموضوع 6 أشهر و3 أشهر للمسائل المستعجلة ويمكن أن تمتـد هذه الفترة الى 3 أشـهر أخرى ويحق للجـان التحقيقيـة من أجل التوصل إلى الحقيقة طلب الاستشارة من الخبر اء ـ

و تقدم لجـان التحكيم تقرير هـا إلى لجـان تسـوية المناز عـات في المدة المحددة ويطرح على الدول الأعضـاء الذين يحق لهم الاعتر اض عليه خلال 10 أيام و إذا لم يتم التوصل إلى حل مرضي، تقدم لجنة التحكيم تقرير ها إلى لجنة تسوية المناز عات تبين فيه نتيجة الحكم إذا توصلت إلى حل. ويمكن استئناف القضايا التحكيمية من قبل لجان الاستئناف وهي تتألف من أشخاص يمتلكون الخبرة العاليـة في مجال التجارة الدوليـة وبعد أن تصدر قرار ات لجـان التحكيم وتمضـي 20 يومـا من عرضـها على الأعضـاء يمكن للجـان تسوية المناز عـات و اعتمـاد القرار ات التحكيميـة في حسال عدم استنئنافها ويعتمد جهاز تسوية المناز عـات تقارير هيئة الاستئناف في حسل عدم [14] الاعتر اض عليه

ونجد أن الاحكام التي نص عليها قانون المر افعات العر اقي غير كافيـة، بل نحتـاج إلى تشكيل هيئات خاصـة بـالتحكيم تختص بالفصل في مناز عات الإغراق التجاري فضلا عن اتباع الوسائل الحديثة بالتحكيم من خلال النص على التحكيم الإلكثروني لذلك نقترح على المشرع العر اقي إضـافة النص الآتي إلى قانون المر افعات (يقع التحكيم بالوسـائل التقليدية والوسـائل الإلكترونيـة تشكل لجان و هيئات خاصة تختص بالفصل في قضايا الإغراق التجاري) أما الوساطة فهي من أحد الوسائل الفعالة والبديلة لحل المنازعات وتتسم بالطبيعة الرضائية تتمثل بوجود شخص محايد صساحب

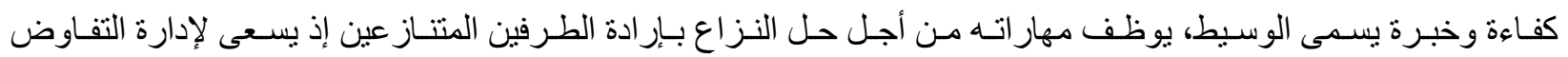
و الوصول لحل يرضي الطرفين وينهي النز اع بينهما بعيدا عن القضاء، ذلك تعد الوساطة من المساعي الطوعية المتخصصـة إذ يتبع الوسيط منهجا متخصصـا لحل النزاع بعيدا عن سـاحة القضـاء مما يؤدي الى تخفيف العبء عن سـاحات القضـاء فضـلا اختصار الوقت والجهد والإجر اءات وتجدر الإشارة إلى أن الوساطة تقوم على عدة أنواع قد تكون قضائية إذ يعين الوسبط فيها من قبل قاضي الإدارة المدنية للاعوى أو تكون وساطة خاصة، إذ يتم اختيار الوسيط من قائمـة تتضمن مجموعة من الوسطاء ذي خبرة وكفاءة عالية أو تكون وسـاطة اتفاقية حيث يتقدم أطر اف النزاع بطلب إلى قاضـي الصلح أو قاضـي الإدارة المدنيـة . [22]وقد نصت منظمة التجارة العالمية على هذه الأساليب لحل مناز عات الإغراق التجاري . أما بالنسبة لموقف المشرع العر اقي فلم ينص على الوساطة لذلك نقترح عليه الأخذ بالوساطة كأسلوب لحل منازعات الإغراق التجاري. 


\section{الخاتمة.}

بعد أن انهينا بحثنا المتو اضع هذا توصلنا إلى جمله من النتائج و التوصيات نوردها على التو الي :

1- - على الرغم من إصدر قانون حماية المنتجات العر اقي والإشارة إلى الإغراق التجاري ضـمن نصوصـه إلا أنه اقتصر على المنتجات فقط، ولم يشمل الخدمات كما أنه أنشار للضرر المادي فقط دون الضرر المعنوي فضلا عن ذلك إنه لم ينظم وسيله قضائية تعالج حالاته كرفع دعوى مدنية، واستحدث المشرع العر اقي محكمة بداءة خاصة بحل المناز عات التجارية ويعد ذللك خطوة إيجابية نحو التخصص القضائي. 2- ل للإغر اق التجاري أنواع منـه الإغراق المؤقت والإغراق الدائم و الإغراق المؤقت لـه نوعان: هما الإغراق المفاجئ و الإغراق قصير الأجل ومن خلال البحث تبين لنا بأن الإغراق القصير الأجل هو أكثر خطورة على المنتج الوطني من أنواع الإغراق التجاري الأخرى.

3- يعاني النظام القضـاء العر اقي عمومـا من ظـاهره البطء في إجر اءات التقاضـي، الأمر الذي يؤثر سلبا على قضـايا المناز عات التجارية ويعود السبب في ذلك إلى عدم تبنيه للنظم القضـائية الحديثة مثل إدارة الدعوى المدنبـة والمحاكم الاقتصادية . 4- تعد الوسائل الحديثة لحل النزاع مثل التحكيم و الوسـاطة وسيلة فعالـه لحل مناز عات الإغر اق التجاري هذا مـا أكدته المنظمة العالمبة للتجارة الدولية، ولم ينص المشرع العر اقي إلا على التحكيم الذي لا تزال نصوصـه بحاجـة إلى إعادة نظر لتشمل التحكيم الإكتروني ليسهل الأخذ بها في مناز عات التجارة الإلكترونية ومنها الإغراق التجاري .

1- نقترح على المشرع العر اقي تعديل نص الفقرة 4 من المادة 1 من قانون حماية المنتجات العر اقية رقم 11 لسنه 2010

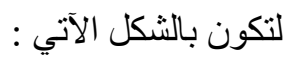
يعد الإغراق مؤقتا كان أم دائميا ممارسة تجارية غير مشرو عة تُباع فيها منتج أجنبي أو تقدم خدمات في أسواق دولـة ما بكميات كبيرة وبثمن أقل من ثمنه في أسواق دولـة المنشـأ أو دولـة ثالثة أو أن يقل عن تكلفة انتاجـة مسببا أضر ار للمنتج الوطني المشابه له . 
إن التعريف المقترح قد أعطى تكيفا دقيقا للإغر اق باعتباره ممارسـة تجاريـة غير مشروعة، كمـا أنه حدد لنـا أنواع الإغر اق و هي المؤقت و الدائمي كما جـاء مفهومـه أوسـع إذ شـل الخدمات و البضـائع معا فضـلا عن ذلك حدد كيفيـة وقوع ممارسة تجارية غير مشروعة، فضلا عن ذلك حدد كيفية وقوع الإغر اق ذلك من خلال بيع المنتجات الأجنيـة بكميات وفيرة وبأثمان أقل بكثير من أثمان المنتج الوطني المشابه له ويترتب على ذلك إضرار ا كبيرة للمنتج الوطني مما يتطلب توفير الحماية القانونية للمنتج الوطني . 2- إن قانون حماية المنتجات العر اقية لم يحدد نوع الضرر الذي يصيب المنتج الوطني، في حين اتفاقية مكافحة الإغراق التجاري قد حددته بالضرر المادي و هذا محل نظر إذ انه لم يثمل الضرر المعنوي لذلك نقترح على المشرع العراقي

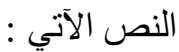
(إذا تحقق الإغراق التجاري لزم التعويض عن مـا يحدثه من أضر ار ماديـة ومعنويـة للمنتج الوطني ) فهذا النص المقترح جـاء واسـعا ليشمل الأضـر ار الماديـة والمعنويـة خاصـة وإن النشـاطات التجاريـة تتأثر بشكل كبير بالسمعة التجارية . 3- لعدم وجود أحكام خاصة بالتعويض عن أضرار الإغراق التجاري من حيث تقديره وشروطه ولعدم كفايـة القو اعد العامة في القانون المدني تقترح على المشرع العر اقي أراد النص الأتي في قانون حماية المنتجات العر اقية: (يحق للمتضررين من الإغراق التجاري المطالبة بالتعويض إن كان له مقتضى ويخضع تقديره للمحاكم الخاصـة في

$$
\text { مسائل الإغراق التجاري ) }
$$

عليه فإن النص المقترح قد عالج مسالة التعويض عن الأضرار الواقعة جراء الإغراق التجاري للمنتج الوطني . 4- ـقترح على المشرع العر اقي إضافة النص الأتي إلى قانون السلطة القضائية تنعقد المحاكم الاقتصـادية في كل محكمـة استئنافيه برئاسـة احد أعضـائها و عضـوية عدد كـافي مـن قضـاتها تخنص بـالنظر في الـدعاوى التجاريـة ودعـاوى الإغراق التجاري . 5- ـوصي المشرع العر اقي بأتباع النظم القضـائية الحديثة التي تنسجم مع طبيعة الدعاوى التجاريـة للتقليل من ظـاهرة البطء في التقاضي مثل نظام إدارة الدعوى المدنية . 6- نقترح على المشـرع العر اقي إضـافة النص الآتي إلى قـانون المر افعات (يقع التحكيم بالوسـائل التقليديـة والوسـائل الإلكترونية وتشكل لجان و هيأت خاصة للفصل في قضايا الإغراق التجاري ) 7- نقترح على المشرع العر اقي أن ينظم أحكام الوساطة كوسيلة لحل مناز عات الإغراق التجاري . 8- إن من أهم الإجر اءات لحماية المنتج الوطني هي فرض رسوم جمركية عالية على البضائع التي تسبب الإغراق . 


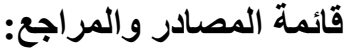

[1] العلامة أبن منظور - معجم لسان العرب المحيط - المجلد 2 - دار لسان العرب - بيروت ـدون سنة طبع . [2] محمد بن أبي بكر بن عبد القادر ـالرازي ــمختار الصحاح ـدار الرسالة ـكويت -1983. [3] ادم و هيب النداوي ,المر افعات المدنية ,دار ابن الاثير ,الموصل 2012. [4] اياد عصام الحطاب ,مكافخة الاغراق التجاري ,دار الثقافة للنشر و التوزيع عمان ,2011, [5] د. أمل شلبي ـ الحد من آليات الاحتكار منع الإغراق و الاحتكار من ألوجهه القانونية ط1 ـ دار ألجامعـه الجديدة 2006- الإسكندرية

[6] حسام الدين عبد الغني الصغير - حماية المعلومات غير المفصح عنها والتحديات التي تواجـه الصناعات الدوائيسة في الدول النائية ــ1 ـ دار الفكر الجامعي الإسكندرية -200335.

[7] د.ر عد حسن الصرن -أساسيات التجارة الدولية المعاصرة- ج1-ط1-دار رضا للنشر سدون ومكان طبع 2000 ـ [8] د.عبد الرزاق السنهوري - الوسيط في شرح القانون المدني ـ ج 1- منشور ات المعارف - بيروت - 2003. [9] عبد الملك عبد الرحمن مظهر ـ الاتفاقيـة الخاصـة في إنشـاء منظمـة التجارة العالميـة ــدار الكتب القانونيةــ القاهرة .2009

[10] د. عادل احمد حشيش - مبادئ الاقتصاد الدولي ــ1990 ـمؤسسة الثقافة الجامعية ـالقاهرة -1990 [11] طلعت محمد دويدار ,المحاكم الاقتصادية خطوة اخرى نحو التخصص القضائي ,دار الجامعة الجديدة , [12] د.محمد انور حامد علي, الاغراق من صور المنافسة الغير مشروعة در اسة مقارنة بين الثريعة الاسـلامية والقانون الوضعي ,دار النهضة العربية ,القاهرة ,2010,

[13] د. علي فوزي الموسوي و عبيد هادي ـ الحماية المدنية للمنتج الوطني من الإغراق التجاري ـ بحث منشور في

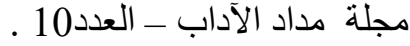

[14] د. عبد الو هاب احمد, دور منظمة التجارة العالمية في تسوية المناز عات التجارية ،بحث منشور في مجلة الدراسـات الاجتماعية, 2010, 2010,

[15] محمد ابو الطيب مقال بعنوان ماهيـة المحاكم الاقتصـادية منشـور على الثـبكة الدوليـة للأنترنيت على الموقع 2020-3-4 تاريخ الزيارةwwwyoum7.com

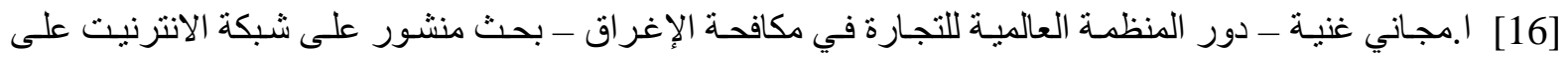
الموقعwww.enssea.net الزيارة 2020/3/4 في السية السعة 5:16. wWw.arab -ency .com .sy. ماهر ملندي - الإغراق التجاري -بحث منشور في شبكة الانترنيت ]17] تاريخ الزيارة في 2020/3/4 في الساعة 4:20 .

[18] د. نغم حسين نعمة - سياسة الإغراق وسبل دعم وحماية المنتج المحلي ـ تطبيقات مختارة مع التركيز على العراق - بحث منشور مجلة الغربي للعلوم الاقتصادية والإدارية ـ السنة 181 - المجلد 7 العدد 30 - 2014 
[19] إغر اق تجاري - مقالة منشورة على شبكة الانترنيت . Wwww. https ://ar .m. Wikipedia.org تاريخ الزيارة

2020/3/4 الساعة 7:15 17

[20] الدباغ ,مقـال بعنوان انشـاء محكمـة متخصصـة بالدعاوى التجاريـة رمنشور على الثبكة الدوليـة للأنترنيت و على الموقع www.lournt.hanews.com تاريخ الزيارة 4-3-2020

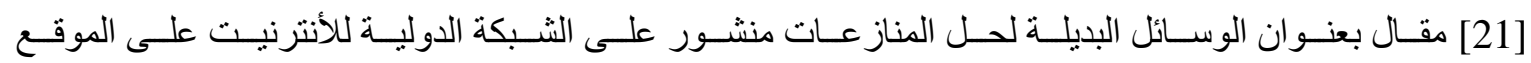
2020-3-5 تاريخ الزيارةwww.droitcivil.over-blog.com

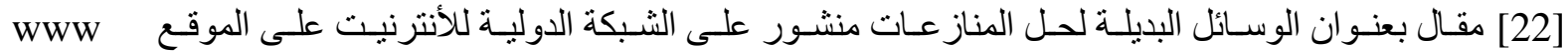
تاريخ الزيارة 5-3020-3020mawdoo3.c0m

[23] قانون حماية المنتجات العر اقية رقم (11) لسنة 2010

[24] قانون المر افعات المدنية العر اقي رقم 83 لسنة 1969

[25] القانون المدني العر اقي رقم (40) لسنة 1951

[26] قانون المحاكم الاقتصادية المصري رقم (12) لسنة 2008 